\title{
The character dynamics problem and emotional education of Vygotsky in children
}

Wu yun te na, College of psychology, Inner Mongolia normal university, China

Lev Vygotsky is a famous psychologist in the Soviet Union, as well as the founder of the school in social cultural history, and the founder of the Soviet Union's child psychology. On the problems of the formation and development of children's characters, Vygotsky has made an excellent study in dynamic and static researches. Especially, he put forward the ideal that the dynamic problems of children's characters formed by a multi-dimensional and multi-level psychological structure. The emotional power, the will power and the rational power of the child's character constitute a very complicated connection, and the development of the character is not simply determined by the external environmental factors, so their connections are not a oneway or static connection, but a two-way interactive dynamic process. Vygotsky 's pioneering research on the idea of children's character dynamics and its application in educational practice had produced a profound influence in the field of education and psychology. In this study, the dynamic thought of the children's character is combed in order to contribute to the development of children's emotion and the research of children's emotional education and we hope it can throw light on the further research. 